University of Vermont

UVM ScholarWorks

Larner College of Medicine Fourth Year

Advanced Integration Teaching/Scholarly

Projects

2021

\title{
Water Pollution and Environmental Concerns in Anesthesiology
}

\author{
Marc Kostrubiak \\ University of Vermont, marc.kostrubiak@med.uvm.edu \\ Christine Vatovec \\ University of Vermont \\ Lesley-Ann Dupigny-Giroux \\ University of Vermont \\ Donna Rizzo \\ University of Vermont \\ William Paganelli \\ University of Vermont
}

See next page for additional authors

Follow this and additional works at: https://scholarworks.uvm.edu/m4sp

Part of the Anesthesiology Commons, Chemicals and Drugs Commons, and the Environmental

Sciences Commons

\section{Recommended Citation}

Kostrubiak, Marc; Vatovec, Christine; Dupigny-Giroux, Lesley-Ann; Rizzo, Donna; Paganelli, William; and Tsai, Mitchell, "Water Pollution and Environmental Concerns in Anesthesiology" (2021). Larner College of Medicine Fourth Year Advanced Integration Teaching/Scholarly Projects. 15.

https://scholarworks.uvm.edu/m4sp/15

This Manuscript is brought to you for free and open access by the Larner College of Medicine at UVM ScholarWorks. It has been accepted for inclusion in Larner College of Medicine Fourth Year Advanced Integration Teaching/Scholarly Projects by an authorized administrator of UVM ScholarWorks. For more information, please contact scholarworks@uvm.edu. 


\section{Authors}

Marc Kostrubiak, Christine Vatovec, Lesley-Ann Dupigny-Giroux, Donna Rizzo, William Paganelli, and Mitchell Tsai 


\section{Title: Water Pollution and Environmental Concerns in Anesthesiology}

Authors: Marc Kostrubiak, $\mathrm{MA}^{1}$; Christine M. Vatovec, $\mathrm{PhD}^{2}$; Lesley-Ann Dupigny-Giroux,

$\mathrm{PhD}^{3}$; Donna M. Rizzo, $\mathrm{PhD}^{4}$; William C. Paganelli, MD, $\mathrm{PhD}^{5}$; Mitchell H. Tsai, MD, MMM${ }^{5-7}$

${ }^{1}$ University of Vermont Larner College of Medicine, Burlington, VT

${ }^{2}$ Rubenstein School of Environment and Natural Resources, University of Vermont, Burlington,

VT

${ }^{3}$ Department of Geography, University of Vermont, Burlington, VT

${ }^{4}$ School of Engineering, University of Vermont, Burlington, VT

${ }^{5}$ Department of Anesthesiology, University of Vermont Larner College of Medicine, Burlington, VT

${ }^{6}$ Department of Orthopaedics and Rehabilitation (by courtesy), University of Vermont Larner College of Medicine, Burlington, VT

${ }^{7}$ Department of Surgery (by courtesy), University of Vermont Larner College of Medicine, Burlington, VT

1. Author: Marc Kostrubiak, MA
a. Title: Medical Student
b. Affiliation: University of Vermont Larner College of Medicine Burlington, VT
c. Email: marc.kostrubiak@med.uvm.edu
d. Financial Disclosures: None
e. Conflicts of Interest: None
f. Clinical Trial Number: N/A
g. Contribution: The author helped create, prepare and edit the manuscript.

2. Author: Christine $\mathrm{M}$. Vatovec, $\mathrm{PhD}$

a. Title: Research Assistant Professor, GUND Fellow

b. Affiliation: Rubenstein School of Environment and Natural Resources, University of Vermont Larner College of Medicine Burlington, VT 
c. Email: christine.vatovec@uvm.edu

d. Financial Disclosures: None

e. Conflicts of Interest: None

f. Clinical Trial Number: N/A

g. Contribution: The author helped create, prepare and edit the manuscript.

3. Author: Lesley-Ann Dupigny-Giroux

a. Title: Professor and Vermont State Climatologist

b. Affiliation: Department of Geography, University of Vermont, VT

c. Email: ldupigny@uvm.edu

d. Financial Disclosures: None

e. Conflicts of Interest: None

f. Clinical Trial Number: N/A

g. Contribution: The author helped create, prepare and edit the manuscript.

4. Author: Donna M. Rizzo, PhD
a. Title: Professor
b. Affiliation: School of Engineering, University of Vermont, Burlington, VT
c. Email:drizzo@uvm.edu
d. Financial Disclosures: None
e. Conflicts of Interest: None
f. Clinical Trial Number: N/A
g. Contribution: The author helped create, prepare and edit the manuscript.

5. Author: William C. Paganelli, MD, PhD
a. Title: Professor
b. Affiliation: Department of Anesthesiology, University of Vermont Larner College of Medicine, Burlington, VT
c. Email: william.paganelli@uvmhealth.org
d. Financial Disclosures: None
e. Conflicts of Interest: None
f. Clinical Trial Number: N/A
g. Contribution: The author helped create, prepare and edit the manuscript.

6. Author: Mitchell H. Tsai, MD, MMM 

a. Title: Associate Professor
b. Affiliation: Department of Anesthesiology, Orthopaedics and Rehabilitation (by courtesy), and Surgery (by courtesy), University of Vermont Larner College of Medicine Burlington, VT
c. Email: mitchell.tsai@uvmhealth.org
d. Financial Disclosures: None
e. Conflicts of Interest: None
f. Clinical Trial Number: N/A
g. Contribution: The author helped create, prepare and edit the manuscript.

\section{Corresponding Author:}

Mitchell H. Tsai, MD, MMM

Associate Professor

Department of Anesthesiology

University of Vermont Medical Center

111 Colchester Avenue

Burlington, VT 05401

Keywords: environment, anesthesia, water, pollution, externalities, pharmaceuticals

Funding: Marc Kostrubiak received \$1,500 received from the Larner College of Medicine

Office of Medical Student Education and \$1,500 matched by the University of Vermont

Department of Anesthesiology for a medical student summer research fellowship from June to August 2018. All UVM first year medical students are eligible for the research fellowship and the application required a two-stage review process.

Disclosures: None

Total Word Count: 2898

Abstract Word Count: 343

Discussion Word Count: 2025 


\begin{abstract}
Medications administered by anesthesia health care providers and subsequently excreted into the water supply system have the potential to affect ecological systems. Presently, there is a lack of literature examining which medications or metabolites enter the waste stream. Further, assessments of their potential environmental impact are often unknown or simply not considered as an externality of medical practice. Recent work examining the practice of anesthesiology has explored the solid waste stream, and the global warming potential of anesthetic gases, however the potential aquatic impacts remain unexplored. To address the potential for waterborne pollution and environmental toxicity, we extracted the total intravenous medications (by mass) administered by anesthesiologists in 2017 at The University of Vermont Medical Center (UVMMC), a mid-size regional Level 1 trauma center in Burlington, VT. The most commonly administered medications were: cefazolin, propofol, acetaminophen, sugammadex and lidocaine. To estimate the amount of each medication that entered the wastewater stream, we used published metabolism profiles to adjust from the total amount administered to the amount excreted unchanged or as prominent metabolites. For each medication we reviewed existing literature concerning their environmental fate and impacts in water. Due to the constraints of current knowledge, it is not possible to determine the exact fate and impacts of these drugs. Some medications, like propofol, have the potential for significant bioaccumulation and persistence. Others, such as lidocaine and acetaminophen, have short half-lives in the environment but their constant delivery and excretion result in pseudo-persistence. The current literature mostly assesses acute exposure at doses higher than could be expected in the environment on select species. While significant toxicities across a variety of species have been found repeatedly, chronic low dose exposures require further study for all the medications
\end{abstract}


discussed. Finally, multi-drug impacts are likely to be more impactful than single-drug toxicities. While we cannot state definitive impacts, the pharmaceuticals most used in anesthesiology have a clear toxic potential and future studies should more closely examine the relative contribution of anesthesia to pharmaceutical pollution, as well as points of intervention for minimizing these unintended consequences of healthcare delivery.

\section{Introduction}

As large-scale industrial facilities that operate $24 / 7$ every day of the year with a mandate of supporting human health, hospitals have an opportunity and responsibility to promote practices that minimize environmental damage [1,2]. Healthcare facilities have been estimated to produce almost $10 \%$ of total greenhouse gases in the U.S. [3], and at over 4 billion tons of waste each year, the healthcare industry as a whole produces is the second largest source of waste in the U.S. [4]. Many calls to action have been placed to reduce the unintended environmental and public health consequences of medical care [5-7], and efforts by several national and international organizations-including Health Care Without Harm, Practice Greenhealth, the Green Guide for Healthcare, and the Healthier Hospitals Initiative-are already underway to reduce healthcare's ecological footprint. Surgery and the entire perioperative process are areas that appear to remain major drivers of resource use and pollution in healthcare.

Within healthcare, surgical departments and operating rooms (OR) are extremely costly, accounting for about $40 \%$ of hospital costs. Although perioperative processes account for $40 \%$ of costs, they may actually be responsible for $70 \%$ of hospital wastes [8]. Previous research on the environmental consequences of medical care suggest that high costs of care correspond, in part, to a heavy reliance on medical supplies, including single-use materials which each have potentially large ecological footprints that accumulate throughout the supply chain from resource 
extraction, manufacturing, processing, packaging, transport, and disposal [5,9]. ORs use a wide variety of resources from water and plastics to anesthesia gases, all of which have different environmental impacts. Further, lifecycle considerations given the choice between disposable and washable equipment carries its own complexity. Previous studies have found that a single procedure could create more waste than that produced over a week by a family of 4 [10]. A single surgeon scrubbing in for a procedure can use 50 liters of water [11].

OR management could become more sustainable should hospital systems focus on and mitigate any potential waste streams. For example, previous work analyzing hand surgery found that eliminating just a handful of extraneous items from disposable packs used in those procedures accounted for over $\$ 40,000$ in annual savings [12]. Also, a larger commercial effort to recycle OR equipment saved over 2000 tons of landfill waste and nearly \$140 million in 2008 alone [12]. Presumably, the reduction of materials consumed in the OR has a three-fold benefit: it saves the hospital money and thus reduces the cost of procedures; decreased procedural costs lower health care expenses, possibly stemming the ballooning cost of health in the U.S.; and finally, it mitigates the environmental externalities inherent to the provision of perioperative care.

While previous work has analyzed the impacts of anesthesia gases and solid waste resulting from ORs [13-16], there is a dearth of literature regarding the intravenous medications used and their impact on surface waters. Medications, given in high quantities during the perioperative process, are metabolized and excreted into hospital and municipal waste water systems. Although hospital wastewater is typically treated via municipal wastewater treatment facilities, these facilities are not designed to remove the myriad of chemicals and agents that are administered in healthcare [17] and are known sources of pharmaceuticals in the environment 
[18-20]. In national reconnaissance studies, pharmaceuticals have been detected in $80 \%$ of surface waters tested in the U.S. [21] and $100 \%$ of 25 large municipal drinking water systems [22].

While the relative contribution of various sources is unknown, hospital wastewater plays a role in the pharmaceutical pollution of surface waters. In order to examine the potential environmental impacts of those medications on its receiving waters of Lake Champlain (which lies between Vermont and New York), we extracted the total intravenous medications (by mass) administered by anesthesiologists in 2017 at The University of Vermont Medical Center (UVMMC), a mid-size regional Level 1 trauma center in Burlington, VT. All medications are tracked on PICIS (Picis Clinical Solutions, Inc., Wakefield, MA). Wastewater from the UVMMC is treated by the Burlington Department of Public Works prior to being released into Lake Champlain. Of note, Lake Champlain is the primary source for Burlington's public drinking water supply.

\section{Discussion}

In 2017, anesthesia health care providers administered over 35 kilograms of medications with varied potentials for concern at the University of Vermont Medical Center, the five most common medications were Cefazolin, Acetaminophen, Sugammadex, Lidocaine and Propofol (Table 1). The Burlington's wastewater treatment plants process all of the hospital effluent. These plants use conventional activated sludge technologies and are occasionally unable to process all wastewater resulting in untreated water entering Lake Champlain without treatment $[23,24]$.

Cefazolin 
Cefazolin, an antibiotic administered for surgical prophylaxis, represents the largest drug by mass administered during the perioperative process at UVMMC in 2017. Cefazolin was given 13,003 times for a total of $23.81 \mathrm{~kg}, 20 \mathrm{~kg}$ more than the next highest mass drug. Not only is cefazolin administered frequently, but it is also one of the most wasted and discarded antibiotics [25]. This suggests that the total amount of cefazolin that enters the waste-stream from the practice of anesthesia could be significantly greater than the total administered to patients due to cefazolin that is discarded rather than administered to patients. Cefazolin does not undergo significant metabolism and is excreted by the kidneys unchanged [26]. Thus, potentially all of the $23.81 \mathrm{~kg}$ found their way into the wastewater systems. Cefazolin has been found in general hospital water effluent at concentrations around $6.2 \mathrm{mg} / \mathrm{L}$ and may be reaching the environment in significant quantities [27].

Despite its relatively long history, the environmental effects of cefazolin have not been thoroughly studied [28]. Cefazolin has been shown not to harm green microalgae (Selenastrum capriconutum and Chlorella vulgaris) - cornerstones of the aquatic ecosystems [29]. On the other hand, in the aquatic environment, cefazolin is susceptible to photo-transformation and chlorination into toxic byproducts [30]. Further, cefazolin is known to be highly teratogenic in zebra fish at $100 \mu \mathrm{g} / \mathrm{mL}$ (as compared to the $6.2 \mu \mathrm{g} / \mathrm{mL}$ found in hospital effluent) and thus, may have significant impacts on aquatic environments [31,30].

Current conventional wastewater treatment does not fully remove cefazolin and other cephalosporins. Cefazolin has been measured entering wastewater plants from 0.08 to 8.79 $\mu \mathrm{g} / \mathrm{mL}$ and leaving those plants at levels as high as $3.8 \mu \mathrm{g} / \mathrm{mL}$ [32]. While these measurements came from Hong Kong which is clearly quite different from Burlington, Vermont they highlight the incomplete removal of cefazolin by wastewater treatment plants. Two wastewater treatment 
methods - photolysis and adsorption - can remove cefazolin; however, results are inconsistent and further technologies may be required for full removal from wastewaters [30]. Although photolysis is a technology designed to remove chemicals, its use may be unwise in the context of cefazolin removal given the potential for toxic by-products. Despite unclear aquaticenvironmental concerns, the growing numbers of antibiotic-resistant bacteria in wastewater treatment plants should prove alarming [30].

\section{Propofol}

Propofol was the second most administered drug by mass at $3.70 \mathrm{~kg}$ distributed in 48,500 doses. The amount of propofol in the hospital waste-stream is likely substantially larger as it is one of the most wasted medications whereby $1 / 3$ to $1 / 2$ of the drug is usually discarded rather than administered to patients $[25,33]$. As one of the cornerstone drugs of anesthesia, understanding its potential impact is crucial. Less than $1 \%$ of propofol is excreted unchanged while about $60 \%$ undergoes hepatic glucuronidation and the remainder is oxidized into several different quinol products [34],[35]. Therefore, a maximum of $37 \mathrm{~g}$ of unchanged propofol could have ended up into the water system.

Although propofol levels in French hospital wastewater streams approach $17.5 \mu \mathrm{g} / \mathrm{L}$, it appears that the drug does reach wastewater treatment plants [36]. However, other studies show higher levels of propofol leaving wastewater treatment plants than in the incoming waters, potentially due to de-glucuronidation [37]. Approximately 60 times more propofol is excreted in the glucuronidated form than the native formulation. Therefore, it is possible that any measured levels are drastically underestimating the potential amount in waters. Given the significant amount of glucuronidated propofol, the contribution from anesthesia services at the UVMMC 
may have up to an additional $2.22 \mathrm{~kg}$ from de-glucuronidation in addition to the original $37 \mathrm{~g}$ of pure propofol.

While the current evidence on propofol reaching the environment is sparse, there are significant concerns regarding its potential environmental impact. Propofol may bioaccumulate in organisms due to its fat solubility, although studies show lower than theoretically expected results [38]. Ecotoxicity testing has found impacts on a large range of species from growth inhibition and death of algae, to acute toxicity in small crustaceans (Daphnia magna), and freshwater fish (blue gill sunfish and rainbow trout) [38]. There are limited data regarding chronic exposure, although laboratory studies show it impacts the survival, growth and reproduction of Daphnia magna [38]. Understanding long-term exposure is of particular importance because propofol is not readily degraded [38]. Conventional wastewater treatment methods, including aerobic removal by activated sludge or anaerobic digesters are minimally effective [38].

Once in the aquatic environment, propofol is not significantly photolyzed in water [38]. In fact, propofol must be incinerated at $>1000^{\circ} \mathrm{C}$ for over 2 seconds - an impractical target to reach via any standard public water treatment method - to fully remove the drug [25].Additionally, propofol is highly mobile in soils and therefore, may accumulate significantly both on land if deposited via biosolid waste, as well as in water near wastewater release points [38].Aquatic accumulation is particularly likely given the estimated aquatic half-life of greater than 1 year [38]. In sum, propofol has the potential for bioaccumulation, has both acute and chronic aquatic toxicity, and does not readily degrade $[25,38]$. The current manufacturer assessment states that the overall environmental risk is predicted to be low based on less than $1 \%$ of propofol being excreted unchanged [38]. Again, the potential for significant amounts of the 
$\sim 60 \%$ of excreted glucuronidated propofol to become propofol in the environment suggests that the current impact could be 60 times greater than currently estimated.

\section{Acetaminophen}

In 2017, the anesthesia health care service administered a total of $3.35 \mathrm{~kg}$ of acetaminophen over 4478 doses. Acetaminophen is mostly metabolized by kidneys with only $5 \%$ excreted unchanged. Therefore, we estimated that 170 grams of pure acetaminophen (equivalent to 523 standard over the counter pills) were excreted into the water as a result of the practice of anesthesia at UVMMC. Drug metabolism is distributed an average as 55\% apap-glucose, which is divided between renal and biliary excretion; $37 \%$ as apap-sulfate excreted through the kidneys, and 7\% becoming n-acetyl-p-benzoquinone-imine (NAPQI). NAPQI then undergoes a set of reactions concluding with apap-mercapturic acid [39].

Although the perioperative arena only accounts for a small portion of acetaminophen delivered in a hospital system, acetaminophen is one of the most prescribed drugs across the world and is available over the counter in many countries - further necessitating an understanding of its environmental impacts as well as the large amount taken as an over-thecounter medication. Acetaminophen has been found in waters across the US, Europe and the world in concentration as high as $65 \mu \mathrm{g} / \mathrm{L}$ in Great Britain [40]. In the US, it has been detected in $24 \%$ of stream water samples [41] and it has even been found to survive into drinking waters [42].

Due to its frequency, persistence and toxic potential, acetaminophen has been labeled a priority drug for water cycle assessments and is generally considered to have significant ecological hazard potential $[41,43,44]$. While it is well-established that acetaminophen causes hepatotoxicity in humans and mammals at high doses, the aquatic impacts are not as well studied 
[43]. Acetaminophen has been found to be acutely toxic to nearly all species, including bacteria, algae and macrophytes and crustaceans, in a standard battery of aquatic environmental tests organisms including bacteria, microalgae, aquatic plants, and crustaceans [40].Acetaminophen has been found to be specifically neurotoxic to freshwater shrimp and planarians [40]. Of note, the toxicity was elicited at lower doses in the crustaceans than the microorganisms. While these results were seen at doses orders of magnitude greater than currently documented in wastewaters, the potential for non-fatal or non-growth arresting chronic impacts at lower doses is significant and has been demonstrated at doses in the $\mu \mathrm{g} / \mathrm{L}$ range in marine and freshwater clams $[43,40]$. Studies of these bivalves are particularly important as they are crucial elements in ecosystems and are also filter feeders and thus accumulate higher levels of environmental pollutants [43]. Finally, acetaminophen disrupts the endocrine systems and inhibits growth in laboratory studies, highlighting the importance of sub-lethal subacute exposure $[45,46]$. While acetaminophen has a significant potential ecotoxicity, results and concentrations needed to elicit toxicity vary widely in the literature, and more assessments of non-vertebrates, the foundation of many ecosystems, are needed [40].

While acetaminophen is unlikely to survive more than 15 days in the environment [45], pseudo-persistence is a major concern since effluent release areas are constantly bathed with low levels of medications leading to chronic exposure [47-50]. In some regions, 15 days of survival is more than enough time for acetaminophen to distribute across a wide area. Even after degradation, certain photolysis products of acetaminophen may be more toxic than acetaminophen itself, thus further complicating a comprehensive understanding of acetaminophen's environmental impact [51]. Additionally, wastewater effluent also contains countless other medications; and acetaminophen may amplify the toxicity of other drugs 
[40]. While acetaminophen clearly survives into the environment, conventional activated sludge (and more advanced technologies such as membrane bioreactors) have been shown to remove $>98 \%$ of the drug [52-54]. However, given the levels of acetaminophen in the environment is it likely that much higher removal efficiency is needed to truly prevent its ecological impact.

\section{Sugammadex}

Approved by the Federal Drug Administration in 2015, sugammadex has quickly grown to become one of the most used drugs among anesthesia health care providers. In $2017,1.38 \mathrm{~kg}$ of sugammadex was administered over 7,073 doses at UVMMC. Sugammadex is renally eliminated unchanged and it environmental impact is unknown [55]. There is currently a lack of literature regarding its presence in wastewater streams, its toxicity, and its environmental impact. However, it is clear that sugammadex may have significant impacts due to its ability to bind to estrogen and progesterone [56]. Its ability to bind these hormones in humans is so significant that alternate forms of birth control are needed for 7 days after a single dose of sugammadex. With its potential as an endocrine disruptor are warranted, further research into the environmental impacts and especially its potential to be an endocrine disruptor are warranted. Currently, it is unclear whether it reaches the aquatic environment and whether sugammadex is a source of environmental externalities from the practice anesthesia.

\section{Lidocaine}

Lidocaine was administered nearly 16,000 times for a total of $1.02 \mathrm{~kg}$ by UVMMC anesthesiologists in 2017. Lidocaine is excreted in several different forms. Ten percent is excreted unchanged by the kidneys, while $90 \%$ is metabolized. Lidocaine metabolism produces mostly monoethylglycinexylidine (MEGX), the major metabolite, and 2,6-xylidine as its minor product. Both MEGX and 2,6-xylidine undergo renal elimination [57]. MEGX is also further 
metabolized into the potentially carcinogenic 2,6-xylidine [58]. We estimate that 102 grams of pure lidocaine would have been excreted and upwards of $500 \mathrm{~g}$ of MEGX.

Lidocaine and its metabolites have been found in both wastewater and in the environment as they are only partially removed by wastewater treatment [58]. While the metabolites (MEGX and 2,6-xylidine) have been found occasionally in wastewater, lidocaine is not fully removed by treatment and has been found in surface waters and not just waste-streams [58]. While traditional activated sludge treatment is not fully effective against lidocaine, both PAC/GAC absorption and ozonation are effective and thus any potential impacts of lidocaine may be mitigated or prevented [59]. However, lidocaine does not appear to survive long enough in the environment to reach groundwater stores [58].

Despite this presumed potential for environmental degradation, lidocaine has been found at least $3 \mathrm{~km}$ downstream from a wastewater effluent release location [58]. This indicates the potential for environmental persistence particularly near any release points. While lidocaine may be persistent, it is unlikely to bio-accumulate in organisms due to its low lipid solubility. Shortterm tests have not found significant aquatic toxicity from lidocaine; but the long-term studies at the release points and surrounding environments are lacking [60]. Within the Lake Champlain waterways, where the discharge ends in a lake, accumulation over time may be significant.

\section{Conclusion}

Medications administered by anesthesia health care providers and subsequently excreted into the water supply system have the potential to affect ecological systems. Currently, it is not possible to definitively describe the fate of these chemicals in the environment. Some medications, like propofol, have the potential for significant bioaccumulation and persistence. Other drugs, such as lidocaine and acetaminophen, have short half-lives in the environment but 
their constant delivery and excretion result in pseudo-persistence. The current literature mostly assesses acute exposure at doses higher than could be expected in the environment on select species. While significant toxicities across a variety of species have been found repeatedly, chronic low dose exposures require further study for all the medications discussed. Finally, multi-drug impacts are likely to be more impactful than single-drug toxicities $[61,62,49,63,50]$. While the current literature does not allow for definitive statements regarding the impacts of anesthetics in the aquatic environment, they have a clear toxic potential and future studies should more closely examine the relative contribution of anesthesia to pharmaceutical pollution, as well as points of intervention for minimizing these unintended consequences of healthcare delivery.

\section{References}

1. Heilig S, Kushner T, Thomasma D, Agich G, Atchley W, Bayley C, Bauer K, Burack J, Burgess M, Childs B, Cranford R, Daniels N, Daniels S, DeRenzo E, Donohoe M, Dugan D, Dworkin G, Goldworth A, Goodman K, Hardwig J, Hick C, Iserson K, Jameton A, Jonsen A, Kirnsma G, Kennedy L, Kittay E, Koenig B, Lambrinidou Y, Langerman A, Lee P, van Leeuwen E, Light A, Loeben G, Loewy E, Meeker T, Meier D, Moyer F, Mozdzierz G, Nie J, d'Oronzio J, O'Connell L, Picozzi M, Potter V, Radest H, Rubin S, Ruddick W, Scanlon C, Self D, Setlak P, Sharpe V, Silvers A, Smith M, Steinbrook B, Tanner N, Trotter G, Veatch R, Weber L, White M, Winslow G, Wolpe P, Young E, Zoloth L (2002) Healthcare without harm: An ethical imperative. Cambridge Quarterly of Healthcare Ethics 11 (2):203-207

2. Jameton A, Pierce J (2001) Environment and health: 8. Sustainable health care and emerging ethical responsibilities. CMAJ : Canadian Medical Association journal = journal de l'Association medicale canadienne 164 (3):365-369

3. Chung JW, Meltzer DO (2009) Estimate of the carbon footprint of the US health care sector. Jama 302 (18):1970-1972. doi:10.1001/jama.2009.1610

4. Kwakye G, Brat GA, Makary MA (2011) Green surgical practices for health care. Archives of surgery (Chicago, Ill : 1960) 146 (2):131-136. doi:10.1001/archsurg.2010.343

5. Vatovec C, Senier L, Bell M (2013) An Ecological Perspective on Medical Care:

Environmental, Occupational, and Public Health Impacts of Medical Supply and Pharmaceutical Chains. Ecohealth 10 (3):257-267. doi:DOI 10.1007/s10393-013-0855-1

6. Jameton A, Pierce J (2001) Environment and health: 8. Sustainable health care and emerging ethical responsibilities. CMAJ : Canadian Medical Association journal = journal de 1\&\#039;Association medicale canadienne 164 (3):365

7. Jameton A, McGuire C (2002) Toward sustainable health-care services: principles, challenges, and a process. International Journal of Sustainability in Higher Education 3 (2):113-127

8. Albert MG, Rothkopf DM (2015) Operating room waste reduction in plastic and hand surgery. Plastic surgery (Oakville, Ont) 23 (4):235-238 
9. Vatovec C, Senier L, Bell MM (2013) The ecology of dying: commodity chains, governance, and the medicalization of end-of-life care. In: Ecological Health: Society, Ecology and Health. Emerald Group Publishing Limited, pp 195-215

10. Stall NM, Kagoma YK, Bondy JN, Naudie D (2013) Surgical waste audit of 5 total knee arthroplasties. Canadian Journal of Surgery 56 (2):97-102. doi:10.1503/cjs.015711

11. Alfa-Wali M (2009) Surgery and water. Journal of the Royal Society of Medicine 102 (2):81. doi:10.1258/jrsm.2009.090018

12. Potera C (2012) Strategies for Greener Hospital Operating Rooms. Environmental Health Perspectives 120 (8):a306-307. doi:10.1289/ehp.120-a306a

13. Sherman J, Le C, Lamers V, Eckelman M (2012) Life cycle greenhouse gas emissions of anesthetic drugs. Anesthesia and analgesia 114 (5):1086-1090.

doi:10.1213/ANE.0b013e31824f6940

14. Ishizawa Y (2011) Special article: general anesthetic gases and the global environment.

Anesthesia and analgesia 112 (1):213-217. doi:10.1213/ANE.0b013e3181fe02c2

15. Sherman JD, Ryan S (2010) Ecological Responsibility in Anesthesia Practice. 48 (3):139-

151. doi:10.1097/AIA.0b013e3181ea7587

16. Ryan S, Sherman J (2012) Sustainable Anesthesia. 114 (5):921-923.

doi:10.1213/ANE.0b013e31824fcea6

17. Verlicchi P, Al Aukidy M, Zambello E (2012) Occurrence of pharmaceutical compounds in urban wastewater: removal, mass load and environmental risk after a secondary treatment - a review. Science of the Total Environment 429:123-155

18. Azuma T, Nakada N, Yamashita N, Tanaka H (2015) Prediction, risk and control of antiinfluenza drugs in the Yodo River Basin, Japan during seasonal and pandemic influenza using the transmission model for infectious disease. Science of The Total Environment 521:68-74 19. Jain S, Kumar P, Vyas RK, Pandit P, Dalai AK (2013) Occurrence and removal of antiviral drugs in environment: A review. Water, Air, \& Soil Pollution 224 (2):1-19

20. Venkatesan AK, Halden RU (2014) Wastewater treatment plants as chemical observatories to forecast ecological and human health risks of manmade chemicals. Scientific reports 4 21. Kolpin DW, Furlong ET, Meyer MT, Thurman EM, Zaugg SD, Barber LB, Buxton HT (2002) Pharmaceuticals, hormones, and other organic wastewater contaminants in U.S. streams, 1999- 2000: a national reconnaissance. Environmental science \&amp; technology 36 (6):1202 22. Furlong ET, Batt AL, Glassmeyer ST, Noriega MC, Kolpin DW, Mash H, Schenck KM (2017) Nationwide reconnaissance of contaminants of emerging concern in source and treated drinking waters of the United States: Pharmaceuticals. Science of the Total Environment 579:1629-1642

23. Jickling K (2018) Muddied Waters: No Clear Solutions for Burlington's Wastewater

Problem. Seven Days

24. DEC V (2018) WWTF Facility Information.

25. Mankes RF (2012) Propofol wastage in anesthesia. Anesthesia and analgesia 114 (5):10911092. doi:10.1213/ANE.0b013e31824ea491

26. Rein MF, Westervelt FB, Sande MA (1973) Pharmacodynamics of cefazolin in the presence of normal and impaired renal function. Antimicrobial agents and chemotherapy 4 (3):366-371 27. Fatta-Kassinos D, Meric S, Nikolaou A (2011) Pharmaceutical residues in environmental waters and wastewater: current state of knowledge and future research. Analytical and bioanalytical chemistry 399 (1):251-275. doi:10.1007/s00216-010-4300-9 
28. Pfizer Global Environment HaSO (2016) Safety Data Sheet: Cefazolin for Injection (Hospira, Inc.).

29. Eguchi K, Nagase H, Ozawa M, Endoh YS, Goto K, Hirata K, Miyamoto K, Yoshimura H (2004) Evaluation of antimicrobial agents for veterinary use in the ecotoxicity test using microalgae. Chemosphere 57 (11):1733-1738. doi:10.1016/j.chemosphere.2004.07.017 30. Ribeiro AR, Sures B, Schmidt TC (2018) Cephalosporin antibiotics in the aquatic environment: A critical review of occurrence, fate, ecotoxicity and removal technologies. Environmental pollution (Barking, Essex : 1987) 241:1153-1166. doi:10.1016/j.envpol.2018.06.040

31. Zhang J, Meng J, Li Y, Hu C (2010) Investigation of the toxic functional group of cephalosporins by zebrafish embryo toxicity test. Archiv der Pharmazie 343 (10):553-560. doi:10.1002/ardp.201000005

32. Li B, Zhang T (2013) Different removal behaviours of multiple trace antibiotics in municipal wastewater chlorination. Water research 47 (9):2970-2982. doi:10.1016/j.watres.2013.03.001 33. Gordon DM, S. M. (2018) Disposal and Treatment of Controlled Substances from the O.R. ASA Monitor 82:18-21

34. Hiraoka H, Yamamoto K, Miyoshi S, Morita T, Nakamura K, Kadoi Y, Kunimoto F, Horiuchi R (2005) Kidneys contribute to the extrahepatic clearance of propofol in humans, but not lungs and brain. British journal of clinical pharmacology 60 (2):176-182. doi:10.1111/j.13652125.2005.02393.x

35. Favetta P, Degoute CS, Perdrix JP, Dufresne C, Boulieu R, Guitton J (2002) Propofol metabolites in man following propofol induction and maintenance. British Journal of Anaesthesia 88 (5):653-658. doi:10.1093/bja/88.5.653

36. Mullot JU, Karolak S, Fontova A, Levi Y (2010) Modeling of hospital wastewater pollution by pharmaceuticals: first results of Mediflux study carried out in three French hospitals. Water Science and Technology 62 (12):2912-2919. doi:10.2166/wst.2010.986 37. Falås P, Andersen HR, Ledin A, Jansen JlC (2012) Occurrence and reduction of pharmaceuticals in the water phase at Swedish wastewater treatment plants. Water Science and Technology 66 (4):783-791. doi:10.2166/wst.2012.243

38. AstraZeneca (2017) Environmental Risk Assessment Data: Propofol. 39. Mazaleuskaya LL, Sangkuhl K, Thorn CF, FitzGerald GA, Altman RB, Klein TE (2015) PharmGKB summary: pathways of acetaminophen metabolism at the therapeutic versus toxic doses. Pharmacogenetics and genomics 25 (8):416-426. doi:10.1097/fpc.0000000000000150 40. Nunes B, Antunes SC, Santos J, Martins L, Castro BB (2014) Toxic potential of paracetamol to freshwater organisms: A headache to environmental regulators? Ecotoxicology and Environmental Safety 107:178-185. doi:https://doi.org/10.1016/j.ecoenv.2014.05.027 41. Kim Y, Choi K, Jung J, Park S, Kim P-G, Park J (2007) Aquatic toxicity of acetaminophen, carbamazepine, cimetidine, diltiazem and six major sulfonamides, and their potential ecological risks in Korea. Environment International 33 (3):370-375.

doi:https://doi.org/10.1016/j.envint.2006.11.017

42. Damasceno de Oliveira LL, Nunes B, Antunes SC, Campitelli-Ramos R, Rocha O (2018) Acute and Chronic Effects of Three Pharmaceutical Drugs on the Tropical Freshwater Cladoceran Ceriodaphnia silvestrii. Water, Air, \& Soil Pollution 229 (4):116. doi:10.1007/s11270-018-3765-6 43. Antunes SC, Freitas R, Figueira E, Gonçalves F, Nunes B (2013) Biochemical effects of acetaminophen in aquatic species: edible clams Venerupis decussata and Venerupis 
philippinarum. Environmental Science and Pollution Research 20 (9):6658-6666.

doi:10.1007/s11356-013-1784-9

44. de Voogt P, Janex-Habibi ML, Sacher F, Puijker L, Mons M (2009) Development of a common priority list of pharmaceuticals relevant for the water cycle. Water science and technology : a journal of the International Association on Water Pollution Research 59 (1):39-46. doi:10.2166/wst.2009.764

45. de Oliveira LLD, Antunes SC, Gonçalves F, Rocha O, Nunes B (2016) Acute and chronic ecotoxicological effects of four pharmaceuticals drugs on cladoceran Daphnia magna. Drug \& Chemical Toxicology 39 (1):13-21. doi:10.3109/01480545.2015.1029048

46. Guiloski IC, Ribas JLC, Piancini LDS, Dagostim AC, Cirio SM, Fávaro LF, Boschen SL, Cestari MM, da Cunha C, Silva de Assis HC (2017) Paracetamol causes endocrine disruption and hepatotoxicity in male fish Rhamdia quelen after subchronic exposure. Environmental Toxicology and Pharmacology 53:111-120. doi:https://doi.org/10.1016/j.etap.2017.05.005 47. Wu J-P, Li M-H (2015) Inhibitory effects of pain relief drugs on neurological enzymes: Implications on their potential neurotoxicity to aquatic animals. Environmental Toxicology and Pharmacology 39 (2):898-905. doi:https://doi.org/10.1016/j.etap.2015.02.022

48. Daughton CG, Ruhoy IS (2008) The afterlife of drugs and the role of pharmEcovigilance. Drug safety 31 (12):1069-1082. doi:10.2165/0002018-200831120-00004

49. Daughton CG (2003) Cradle-to-cradle stewardship of drugs for minimizing their environmental disposition while promoting human health. I. Rationale for and avenues toward a green pharmacy. Environmental Health Perspectives 111 (5):757

50. Daughton CG, Ternes TA (1999) Pharmaceuticals and personal care products in the environment: agents of subtle change? Environmental Health Perspectives 107 Suppl 6:907-938 51. Ali AMM, Kallenborn R, Sydnes LK, Rønning HT, Alarif WM, Al-Lihaibi S (2017) Photolysis of pharmaceuticals and personal care products in the marine environment under simulated sunlight conditions: irradiation and identification. Environmental Science and Pollution Research 24 (17):14657-14668. doi:10.1007/s11356-017-8930-8

52. Lin AY, Lin CF, Tsai YT, Lin HH, Chen J, Wang XH, Yu TH (2010) Fate of selected pharmaceuticals and personal care products after secondary wastewater treatment processes in Taiwan. Water science and technology : a journal of the International Association on Water Pollution Research 62 (10):2450-2458. doi:10.2166/wst.2010.476 53. Radjenovic J, Petrovic M, Barceló D (2007) Analysis of pharmaceuticals in wastewater and removal using a membrane bioreactor. Analytical and bioanalytical chemistry 387 (4):13651377. doi:10.1007/s00216-006-0883-6

54. Luo Y, Guo W, Ngo HH, Nghiem LD, Hai FI, Zhang J, Liang S, Wang XC (2014) A review on the occurrence of micropollutants in the aquatic environment and their fate and removal during wastewater treatment. The Science of the total environment 473-474:619-641. doi:10.1016/j.scitotenv.2013.12.065

55. Merck Sharp \& Dohme Corp. asoMC, Inc. (2015) Highlights of Prescribing Information: Bridion (sugammadex) Injection, for intravenous use.

56. Tsai MH, Balla A, Tharp WG (2018) Intraoperative Considerations for Transgender Patients. Anesthesia and analgesia. doi:10.1213/ane.0000000000003814

57. Collinsworth KA, Kalman SM, Harrison DC (1974) The clinical pharmacology of lidocaine as an antiarrhythymic drug. Circulation 50 (6):1217-1230 
58. Rua-Gomez PC, Puttmann W (2012) Occurrence and removal of lidocaine, tramadol, venlafaxine, and their metabolites in German wastewater treatment plants. Environmental science and pollution research international 19 (3):689-699. doi:10.1007/s11356-011-0614-1 59. Rua-Gomez PC, Puttmann W (2012) Impact of wastewater treatment plant discharge of lidocaine, tramadol, venlafaxine and their metabolites on the quality of surface waters and groundwater. Journal of environmental monitoring : JEM 14 (5):1391-1399. doi:10.1039/c2em10950f

60. AstraZeneca (2017) Environmental Risk Assessment Data: Lidocaine.

61. Daughton CG, Ruhoy IS (2009) Environmental Footprint of Pharmaceuticals: The Significance of Factors Beyond Direct Excretion to Sewers. Environ Toxicol Chem 28 (12):2495-2521

62. Daughton CG, Ruhoy IS (2008) The Afterlife of Drugs and the Role of PharmEcovigilance. Drug Safety 31 (12):1069-1082. doi:Doi 10.2165/0002018-200831120-00004

63. Daughton CG (2002) Environmental stewardship and drugs as pollutants. The Lancet 360 (9339):1035-1036. doi:10.1016/S0140-6736(02)11176-7 
Table 1. Table of the most common drugs administered by the anesthesia service at the University of Vermont Medical Center in 2017.

\begin{tabular}{|c|c|c|c|}
\hline Drug & mg & kg & Doses \\
\hline Cefazolin & $23,807,414$ & 23.80741 & 13,003 \\
\hline Propofol & $3,696,145.5$ & 3.696146 & 48,500 \\
\hline Acetaminophen IV & $3,350,373.5$ & 3.350374 & 4,478 \\
\hline Sugammadex & $1,384,146.6$ & 1.384147 & 7,073 \\
\hline Lidocaine $2 \%$ IV & $1,019,456$ & 1.019456 & 15,887 \\
\hline Rocuronium & $560,887.73$ & 0.560888 & 17,323 \\
\hline Ketamine IV & $334,560.6$ & 0.334561 & 18,898 \\
\hline Succinylcholine Chloride & 298,443 & 0.298443 & 2,584 \\
\hline Methohexital & 171,585 & 0.171585 & 1,939 \\
\hline Ketorolac & $138,031.4$ & 0.138031 & 5,400 \\
\hline Esmolol & 66,228 & 0.066228 & 2,515 \\
\hline
\end{tabular}

